\title{
Geografía social y red de comunicaciones en el norte de Nueva Galicia: Mazapil (1774-1779)
}

Montserrat Cachero Vinuesa

Universidad de Sevilla

El camino es el medio utilizado en este trabajo para realizar un acercamiento a la realidad socioeconómica de una de las zonas zacatecanas más relevantes. Utilizando como fuentes documentales los padrones de 1774 y 1779 guardados en el Archivo General de Indias, se tratan de esclarecer las dimensiones y actividades económicas y la composición étnica de la población trabajadora que se encontraba asentada en los pequeños núcleos situados a lo largo del Camino Real de la Plata, en el tramo que discurría por la jurisdicción de Mazapil. Es estudiada también la élite propietaria, analizando sus fuentes de riqueza en esta zona. Con todo ello se aporta un estudio que enriquece el conocimiento del noroeste del virreinato de la Nueva España.

La red de comunicaciones construida por los españoles en el Nuevo Mundo poseía una estructura radial; con centro en la antigua Tenochtitlan, y se extendía hacia los cuatro puntos cardinales, surcando gran parte del territorio del virreinato. Así, por el norte, desde la Nueva Vizcaya y pasando por Nueva Galicia, llegaban a la capital metales preciosos, azogue y otros minerales. Estas regiones, famosas también por su riqueza ganadera, se encargaron de exportar reses, porcino y ovino - aunque éstos últimos algo menos importantes en volumen-. La zona del Bajío, situada en el centro de las rutas que iban desde la capital a los centros mineros, se convirtió en el granero de la Nueva España, produciendo sobre todo maíz y trigo, pero también cebada, frijol y chile. Ya desde principios de la colonización, esta región superaba en producción a los centros agrícolas más importantes de Europa, sin embargo siempre fue vista por la Corona en un segundo plano, como suministradora de cereales para las poblaciones mineras del norte. ${ }^{1}$

$\mathrm{Al}$ sur y al norte de la capital mexicana se situaban zonas productoras destacadas, mientras que al este y al oeste estaban los puertos más importantes, puntos estos necesarios para el embarque de las mercancías rumbo a la metrópoli y lugares de recepción de los barcos cargados con manufac-

1 Baroni Boissonas, Ariane: La formación de la estructura agraria en el Bajío colonial. Siglos XVI y XVII. México, 1990, pág. 23. 
turas castellanas y orientales. Por el oeste se encontraba Acapulco y hacia el este uno de los más importantes puertos de la época colonial española: Veracruz.

Uno de los primeros tramos en las comunicaciones terrestres hacia el noroeste fue concluido alrededor de 1550; se trata del Camino Real de la Tierra Adentro, denominado así por tener un interés público, al menos desde el punto de vista oficial. ${ }^{2}$ Inicialmente unía México con Querétaro, pero la increíble expansión territorial llevada a cabo en el XVI trajo como consecuencia inmediata la ampliación de esta ruta hasta Zacatecas. Ya en 1540, el informe del franciscano fray Marcos de Niza sobre las grandes riquezas del norte mexicano, propició que el virrey Mendoza organizara las primeras incursiones hacia la desconocida Gran Chichimeca ${ }^{3}$ y en 1555 ya era posible el tráfico de viajeros y mercancías desde Zacatecas hasta la capital del virreinato. ${ }^{4}$

La villa de Nuestra Señora de los Zacatecas ha sido bautizada por algunos autores como madre y civilizadora del norte de México, porque fue la base de futuras exploraciones y además abastecedora de hombres para la colonización de los territorios conquistados. En palabras de Florescano, "Zacatecas promovió la expansión hacia tierras más septentrionales y la colonización del territorio intermedio que la separaba de sus centros de abastecimiento: México y Guadalajara". ${ }^{5}$ La hostilidad que presentaron los indios chichimecas no supuso un obstáculo insalvable en las exploraciones hacia el norte y así Francisco de Ibarra, ${ }^{6}$ en 1554, llegó al sitio donde más tarde se levantaría Mazapil. ${ }^{7}$

2 Pérez González, M. ${ }^{\mathrm{a}}$ Luisa: "Los caminos reales de América en la legislación y en la historia”. Anuario de Estudios Americanos, LVIII-1, enero-junio, Sevilla, 2001, págs. 33-60.

3 Román Gutiérrez, J. F.: "El Camino Real de la Plata, mito y realidad". México en el tiempo, año 4, n. $^{\circ} 27$. México, 1998, págs.10-18.

4 A lo largo de los siglos XVI y XVII se sucedieron las incursiones en el territorio más septentrional, ampliándose el camino hasta poblaciones como Fresnillo, Nombre de Dios, Durango, Chihuahua o El Paso. Finalmente concluye en Santa Fe del Nuevo México, resultando la vía de comunicación más larga del virreinato. Serrera Contreras, Ramón María: Tráfico terrestre y red vial en las Indias Españolas. Barcelona-Madrid, 1992, págs. 39 y 40.

5 Florescano, Enrique: "Colonización, ocupación del suelo y frontera en el norte de Nueva España, 1521-1750”, en Álvaro Jara (compilador): Tierras nuevas. Expansión territorial y ocupación del suelo en América (siglos XVI-XIX). México, DF, 1969, págs. 43-76.

6 Se trata del sobrino de Diego de Ibarra, uno de los fundadores de Zacatecas y que contribuyó con su capital a futuras exploraciones. Francisco capitaneó esta expedición cuando contaba tan sólo con dieciséis años. Véase Mecham, J. Lloyd: Francisco de Ibarra and Nueva Vizcaya. Durham, North Carolina, 1927.

7 Bakewell, Peter J.: Economía y sociedad en el México colonial. Zacatecas (1546-1700). México, 1976, pág. 48. 


\section{Caminos secundarios}

Los mitos creados en torno a las inmensas riquezas minerales de los nuevos territorios aceleraron el proceso de colonización de los mismos, ${ }^{8}$ pero la difícil geografía de estos lugares favorecía el aislamiento, ${ }^{9}$ así que pronto surge la necesidad de establecer toda una red de caminos que comuniquen entre sí estos nuevos centros productores. Se transformó entonces Zacatecas en el núcleo a través del cual se canaliza el comercio del amplio norte del virreinato.

En fechas cercanas al comienzo de las luchas independentistas, Juan Cruz Ruiz de Cabañas —obispo de Guadalajara—, en su visita a la Nueva Galicia en el año 1805, todavía argumentaba sobre las ventajas de adoptar un sistema de comunicaciones adecuado:

"Así se auxiliarían unos pueblos a otros, porque siendo, como son, tan varios, ricos y abundantes en sus productos, con sólo el cambio de ellos podrían hacerse prósperos y felices". ${ }^{10}$

En los párrafos introductorios hemos señalado la importancia de los puertos y en función de ellos estaban las dos rutas comerciales que atravesaban el centro de la Nueva España: la primera era la que, pasando por Durango, unía después México con Veracruz ${ }^{11}$ la segunda comunicaba la capital con el puerto de Acapulco. ${ }^{12}$ Pero existían localidades que no estaban comprendidas en estos itinerarios y también necesitaban del tráfico comercial, tanto por razones de abastecimiento como para la venta de los productos autóctonos. Una de estas vías secundarias unía Zacatecas con la

8 Frédérique Langue, utilizando una expresión de Arlegui, afirma que el "eco sonoro de la plata" determinó los movimientos demográficos y económicos de la región. Arlegui, P. José de: Crónica de la Provincia de NSPS Francisco de Zacatecas. México, 1851, citado en Langue, F.: "Trabajadores y formas de trabajo en las minas zacatecanas del siglo XVIII". Historia Mexicana, volumen 40, n. ${ }^{\circ}$, México, enero-marzo 1991, págs. 463-506.

9 Este aislamiento viene comprobado por el hecho de que los vecinos de la zona central del virreinato se referían al gran norte como "tierra adentro", mientras que los que habitaban las zonas más septentrionales denominaban "tierra afuera" a la capital de la Nueva España y su periferia. Cramaussel, Chantal : "Tierra Adentro y Tierra Afuera, el septentrión de la Nueva España”, en Mazín Gómez, Oscar (ed.): México en el mundo hispánico. México, 2000, vol. I, pág. 69.

10 Archivo General de Indias (en adelante AGI), Guadalajara, 543. "Estado material y formal de la Diócesis de Guadalajara en el año 1805, por su obispo Dr. Juan Cruz Ruiz de Cabañas”. Citado en Serrera Contreras, Ramón M. ${ }^{\text {a: }}$ Guadalajara Ganadera. Estudio regional novohispano (1760-1805). Sevilla, 1977. Segunda edición, Guadalajara, Jalisco, 1992, pág. 416.

11 Una parte de esta ruta discurría por el Camino Real de la Tierra Adentro.

12 Ambos caminos han sido estudiados por Ramón Serrera en: Tráfico terrestre... 
villa del Saltillo pasando por Mazapil; este camino se realizaba zigzagueando en busca de los escasos aguajes de la zona, con lo cual ocurría que, a veces, las distancias llegaban a duplicarse:

"Por el camino que se camina ordinariamente hay casi 50 leguas desde la ciudad de Zacatecas al Mazapil, de tierra muy llana, dado que por el rumbo seguido no hay 30 ni aún 25 , pero es tierra de tan pocas aguas que se tuerce mucho el camino por buscar aguajes en que parar". ${ }^{13}$

En 1606 la Audiencia de Guadalajara envió al oidor Gaspar de la Fuente a visitar estos territorios y, en relación con la carestía de agua, este juez sostenía que:

"De Zacatecas al Mazapil hay 52 leguas, todas despobladas, y tierra estéril de pastos y aguajes porque es salitral, de manera que sólo animales silvestres y yeguas cimarronas habitan en ella y las aguas son salobres; carecen de ella los caminantes porque caminando todo el día no tienen más que un aguaje en cada uno, por haber de un aguaje a otro 8 y 12 leguas". ${ }^{14}$

Asimismo, todos los viajeros que pasaron por estos lugares coincidían en afirmar que el principal problema era la pobreza de agua, convirtiéndose en un bien de lo más apreciado; esto dificultaba mucho los desplazamientos, sobre todo si se tiene en cuenta que hasta hoy ésta es una zona ganadera y que las reses necesitan de agua y pastos durante su acarreo. La escasez hace que el paisaje sea árido, casi desértico:

"Es tierra muy alta, estéril y que no cría sino espinos y unos árboles que llaman mezquite". ${ }^{15}$

Otra consecuencia era su baja población, concentrándose los pocos habitantes en las haciendas que aparecían a lo largo del camino; tan escasos eran los vecinos en esta zona, que el camino que comunicaba Zacatecas con Saltillo pasando por Mazapil era denominado "camino del infierno", debido a lo poco transitado de esta vía. ${ }^{16}$ Los primeros pobladores fueron los guachichiles, una tribu de cazadores y recolectores, en la que los gue-

13 Arregui, Domingo Lázaro de: Descripción de la Nueva Galicia. Edición de François Chevalier, prólogo de John Van Horne. Sevilla, 1946, pág. 127.

14 Berthe, J. P.: "El licenciado Gaspar de la Fuente y su visita tierra adentro, 1608-1609", en Berthe, J. P. y otros: Sociedades en construcción. La Nueva Galicia según las visitas de oidores (16061616), Guadalajara, Jalisco (México), 2000, págs. 95-155, pág. 107.

15 Arregui, Domingo Lázaro de: Descripción..., pág. 128.

16 Cramaussel, Chantal: “Tierra Adentro...”, pág. 75. 
rreros demostraban una gran destreza en el manejo del arco y la flecha. Estos indígenas desarrollaron una excelente capacidad para sobrevivir en las circunstancias climáticas más adversas ${ }^{17} \mathrm{y}$ las noticias sobre la belicosidad de este pueblo atrajeron a un considerable número de soldados españoles que, desde Mazapil, iniciaron exploraciones hacia lugares como Saltillo o Monterrey.

La presencia española se incrementó con el descubrimiento de las primeras vetas de plata de la zona, pero el agotamiento de las mismas y la mala calidad del mineral extraído provocó, a lo largo del siglo XVI, el abandono temprano de algunas de estas explotaciones mineras en la zona de Mazapil:

"Treinta leguas hacia el poniente está el Real de las minas del Mazapil que fueron muy prósperas en su descubrimiento del beneficio de fundición, y agora no lo son tanto, porque los metales se van acabando, y los que ay no son de tan buena ley". ${ }^{18}$

Aunque la extracción de metales preciosos como el oro y la plata fue de duración efímera, no ocurrió lo mismo con otros metales y Mazapil se transformó en un punto estratégico en el camino que comunicaba los principales reales mineros —el llamado Camino Real de la Plata $^{19}$ — pues era productora de cobre y plomo, materiales necesarios para el beneficio del resto de minas de la región:

"Las minas de Mazapil están por lo más cercano 42 leguas de población de cristianos, y son de mucha importancia porque se saca de ellas greta y cendrada y plomo para el beneficio de las minas del Sombrerete y el Fresnillo y las de Zacatecas y otras muchas que se benefician por fundición, y hay minas de esta población, cobrizas muchas y ricas". ${ }^{20}$

Aunque esta ruta era mucho más amplia, nos centramos tan sólo en aquella parte que transcurre por el distrito estudiado, es decir, la que iba desde Nieves y pasando Mazapil, trasladaría los minerales hasta Zacatecas.

17 Román Gutiérrez, J. F.: "El Camino...”, pág. 14.

18 Mota y Escobar, Alonso de: Descripción geográfica de los reinos de Nueva Galicia, Nueva Vizcaya y Nuevo León. Edición de José Luis Razo Zaragoza y José Parres Arias. Guadalajara, 1966, pág. 72.

19 Román Gutiérrez, J. F.: "El Camino...”, pág. 13.

20 AGI, Indiferente General, 1090, ramo 11, número 297. Citado en Román Gutiérrez, J. F., Martín Ornelas, J. M. y Ramírez Ramos, A.: “ Mazapil a finales del siglo XVIII: un acercamiento a su población”. Estudios del Hombre. Historia y genealogía del Occidente de México, número de homenaje a Jorge Palomino, n. ${ }^{\circ}$ 6, Guadalajara, Jalisco, 1997, págs. 219-237. 
La ganadería, al igual que en el resto de reales mineros, comienza a desarrollarse como una actividad paralela a la extracción de metales, pero la temprana decadencia de la minería de la plata origina que la cría de ganado se configure como la actividad económica preponderante en esta región. Ayudado por la concesión de mercedes de tierras, ${ }^{21}$ comienza a configurarse esta jurisdicción como un conjunto de grandes latifundios propiedad de españoles, que solían tener su residencia habitual en la ciudad de México. La población era sobre todo india y el número de españoles quedaba reducido a los cargos de la administración pública y al personal encargado de la dirección u organización de las distintas haciendas.

Para la actividad en esas haciendas era necesario contar con un gran número de trabajadores, pero la escasez de pobladores obligó a los propietarios a traer mano de obra esclava, que sería empleada mayoritariamente en las minas. Aunque en número reducido, este último grupo racial dio lugar a que en el siglo XVIII novohispano un sector considerable de la población fuese mulato; así, para el caso del valle de Oaxaca, Taylor afirma que, aunque la mayoría de los residentes en las haciendas eran indios, había también bastantes mestizos y mulatos. ${ }^{22}$

El camino de Zacatecas hacia Mazapil era facilitado por la existencia de varias haciendas que, además de poblarlo, aseguraban esa ruta. Las más importantes se comentan a continuación.

\section{Pozo Blanco y Sierra Hermosa}

Partiendo de Zacatecas hacia el norte en dirección a Pánuco, el primer aguaje se encuentra ya en la jurisdicción del Mazapil; era la hacienda de San Miguel del Pozo Blanco que, como su propio nombre indica, surgió a partir de un manantial de agua. ${ }^{23} \mathrm{La}$ única referencia a este núcleo se

21 Flores Olague, J.: La fragua de una leyenda. Historia Mínima de Zacatecas. México, 1995, págs. 69-71.

22 Taylor, William B.: Landlord and Peasant in colonial Oaxaca. Stanford, California, 1972, pág. 148.

23 Dada la escasez de agua de estos terrenos, la ubicación de las grandes propiedades solía coincidir con la existencia de aguajes, necesarios para mantener el ganado y beneficiar los metales. Según el testimonio del oidor Gaspar de la Fuente: "En la dicha población ni en su cercanía de más de 12 leguas no hay agua, árbol ni leña de provecho; sólo hay 4 pozos, los tres en las haciendas y el uno para los indios guachichiles, de do beben gente y animales y en tiempo de seca se padece mucho, de manera que las justicias suelen repartir el agua y mueren muchas mulas, que es el género en que se traen los metales". Berthe, J.P.: "El licenciado...”, pág. 120. 
encuentra en el testimonio del viaje a los presidios internos de Nicolás de Lafora, en 1768:

"Día tres (Enero). Anduvimos siete leguas al S. 1/4 S.O. por terreno como el día anterior; a una legua está la pastoría de San Miguel del Pozo Blanco, donde hay cuatrocientas personas empleadas en guardar ochenta mil cabezas de ganado menor, que apacientan en las llanuras de los contornos". ${ }^{4}$

Según el censo de $1779,{ }^{25}$ la población de esta hacienda era de 389 personas, resultando un total de 61 familias, lo cual arroja una media de 6’37 individuos por familia. En cuanto a la distribución por sexos, el $51^{\prime} 67 \%$ de mujeres y por defecto un 48 '33\% de hombres. Aunque el porcentaje de féminas era algo superior, ambos se acercaban al $50 \%$.

También se puede realizar un estudio desde el punto de vista étnico, para esclarecer como se fue desarrollando el fenómeno del mestizaje:

\begin{tabular}{lccccc} 
& Español & Mestizo & Mulato & Indio & Otros \\
\hline Hombre & 6 & 1 & 105 & 53 & 23 \\
Mujer & 3 & 0 & 93 & 72 & 33
\end{tabular}

La población mayoritaria estaba compuesta por mulatos, que suponían un 50'89\%, seguidos del grupo de los indios con un 32'13\%, siendo los demás grupos minoritarios. La presencia española es casi inexistente, pues al ser una hacienda de pastoreo - y no de las mayores - no necesitaba mucho personal para su administración. En toda la jurisdicción de Mazapil el número de esclavos era prácticamente nulo y los pocos existentes se dedicaban a labores domésticas en casa de españoles o al beneficio de metales en las grandes haciendas mineras (como Bonanza, Cedros y Sierra Hermosa); sin embargo, al ser tan frecuente la mezcla entre las distintas razas, los mulatos llegarían con el tiempo a convertirse en el mayor de los grupos que integraban la población de esta hacienda, como ya hemos adelantado de forma general.

24 Lafora, Nicolás de: Relación del viaje que hizo a los presidios internos situados en la frontera de la América Septentrional. Edición de Vito Alessio Robles. México, 1939, pág. 259.

25 AGI, Guadalajara, 348. Expediente formado en cumplimiento de la Real Cédula de 21 de Enero del año 1772 sobre que por los señores virreyes, presidentes y gobernadores se habilitase un plan general de los curatos que comprenden sus distritos; y éste es el respectivo al Gobierno y Obispado de la Nueva Galicia. Cuaderno de Padrones de San Gregorio del Mazapil. 
En un análisis breve sobre las razas y castas en relación con el estado civil de los individuos que poblaban este núcleo, mientras que la mayoría de los escasos trabajadores españoles permanecían solteros, eran muy frecuentes las uniones entre mulatos e indios, resultando un grado de mestizaje bastante elevado, en sus distintos tipos.

Pero Pozo Blanco dependía de una hacienda mayor situada a una legua al sur; ${ }^{26}$ se trata de Sierra Hermosa. Ambas eran propiedad de Miguel del Berrio y Zaldívar, marqués de Jaral del Berrio, ${ }^{27}$ y de su esposa Ana María de la Campa y Cos, condesa de San Mateo de Valparaíso. ${ }^{28}$ Don Miguel pertenecía a la alta administración, era miembro del Consejo Superior de Hacienda, contador del Real Tribunal de Audiencia y Cuentas de la Nueva España, alcalde ordinario y corregidor de la ciudad de México. ${ }^{29}$ Fue también caballero de la Orden de Santiago, ${ }^{30}$ y como un auténtico señor feudal, disponía de una hueste privada que representaba la fuerza de los mineros de la región. ${ }^{31}$ Su esposa, Ana María, era hija primogénita y heredera del coronel español Fernando de la Campa Cos, al que le fue concedido el título de conde por sus hazañas durante la campaña de pacificación de Nayarit. ${ }^{32}$

La residencia de los marqueses de Jaral del Berrio era una de las más famosas de la ciudad de México. Situada en la calle San Francisco y con un coste superior a los 100.000 pesos, el primer marqués gastó fuertes sumas en transformar un antiguo convento en esa soberbia mansión. ${ }^{33}$ En esta residencia palaciega vivía el matrimonio junto con su única hija - Mariana del Berrio y de la Campa- y el esposo de ésta, el marqués de Moncada y Villafort, de origen siciliano. Al igual que la mayoría de los

26 Langue, F.: Los señores de Zacatecas. Una aristocracia minera del siglo XVIII novohispano. México, 1999, pág. 305

27 El título de marqués de Jaral del Berrio fue concedido por Carlos III el 18 de diciembre de 1774. Atienza, Julio de: Títulos nobiliarios hispanoamericanos. Madrid, 1947, pág. 163.

28 El título de conde de San Mateo de Valparaíso data de 1727 y le fue otorgado al coronel don Fernando de la Campa Cos, padre de doña Ana María, por Felipe V. Chevalier, François: La formación de los latifundios en México. Haciendas y sociedad en los siglos XVI, XVII y XVIII. México, 1999, págs. 54-55.

29 Langue, F.: Los señores..., pág. 264.

30 Atienza, J.: Títulos..., pág. 164. Sobre nobleza véase también García Carraffa, Alberto y Arturo: Enciclopedia heráldica y genealógica hispanoamericana. Diccionario heráldico y genealógico de apellidos españoles y americanos. 85 volúmenes, Madrid, 1919.

31 Langue, F.: Los señores..., pág. 211.

32 Chevalier, F.: La formación..., pág. 54.

33 Ladd, Doris M.: La nobleza mexicana en la época de la Independencia, 1780-1826. México, 1984, págs. 94-95. 
nobles de la época, llevaban una vida basada en el lujo y la ostentación requerida por su rango y teniendo en cuenta que los propios oficiales reales se encargaban de amonestar a todas aquellas familias que no podían llevar un estilo de vida acorde con el honor de poseer un título de Castilla. ${ }^{34}$

Miguel del Berrio es el ejemplo de hombre emprendedor que, una vez que ha reunido el suficiente capital, solicita un título de nobleza. La mayoría de su riqueza la obtiene de la minería, pero diversifica sus inversiones destinando grandes sumas a la agricultura, hasta tal punto de que llega a garantizar la subsistencia de los habitantes de Guanajuato y otros centros mineros en períodos de crisis. ${ }^{35}$ También se dedicó a conceder créditos a otros mineros, con lo que garantizó a sus herederos una seguridad económica excepcional. Se opone por tanto al prototipo del noble ocioso que vivía de sus rentas.

Cuando el marqués de Jaral falleció en 1779, dejó a su viuda una de las mayores fortunas de todo el virreinato. Comprendía el mayorazgo del Jaral, en el que se incluía la hacienda del mismo nombre y toda una serie de propiedades tan extensas que los familiares podían ir de Cuatitlán a Durango sin abandonar sus posesiones ${ }^{36}$ Pero la herencia pasó directamente a su nieto, pues en 1774 Francisco Javier Gamboa — regente de la Audiencia de México y amigo personal de Miguel del Berrio- aceptó el cargo de albacea, ante el temor del marqués de que su hija malgastara la fortuna familiar y se deshiciera de todas las propiedades..$^{37}$ miento:

En el padrón de esta hacienda matriz consta el siguiente encabeza-

"Padrón de habitantes de la Hacienda de Sierra Hermosa perteneciente al Conde San Mateo de Valparaíso cuyos individuos vivientes se ocupan en el exercicio de pastores, bacieros y vaqueros". ${ }^{38}$

Estas son actividades muy similares a las que se desarrollaban en la hacienda contigua de Pozo Blanco, y es que los condes de San Mateo de

34 Ibídem.

35 La subsistencia viene determinada por el abastecimiento de alimentos en esta zona, sobre todo en períodos de sequía. Véase Langue, F.: Los señores..., pág. 194.

36 Ibídem.

37 El temor del marqués estaba bien fundado, pues “[...] ella y su marido siciliano peleaban en público, estaban separados, probablemente se eran mutuamente infieles, y estaban ansiosos de dilapidar la cuantiosa herencia que les esperaba, como todo el mundo sabía". Brading, David A.: Mineros y comerciantes en el México borbónico (1763-1810). Madrid, 1975, pág. 104.

38 AGI, Guadalajara, 348. Expediente formado... 
Valparaíso eran una de las grandes familias ganaderas de la Nueva Galicia. ${ }^{39}$ En este sentido, Lafora realizaba la siguiente descripción:

“[...] Lo demás es lomería suave, siguiendo todo el terreno así; las 8 leguas, que hay de dicho puerto a la pastoría llamada los Pozos de San Benito y Sierra Hermosa; consiste su población en 500 personas que se emplean en guardar ciento nueve mil cabezas de ganado menor, que pacen en los inmensos llanos pertenecientes a la pastoría, donde hay mucha grama, bastantes mezquites, uñas de gato, tasajos y algunos otros matorrales". 40

Esta propiedad creció arropada por una fuente de agua; en realidad se trataba de la laguna del Pinto, situada a una legua de camino, que a veces solía secarse pero mediante el sistema de norias y jagüeyes se extraía de ella el agua necesaria para afrontar estos períodos de escasez.

Aunque en 1768 Lafora recoge una población de 500 personas, el censo de 1779 arroja una cifra total de 642 habitantes, con una media de 5'23 individuos por familia, número algo inferior al de la vecina propiedad de Pozo Blanco. Del total de trabajadores de la hacienda, el 50'62\% son mujeres y el 49'38\% hombres; se trata de una distribución bastante homogénea, aunque no ocurre lo mismo cuando se indican las razas:

\begin{tabular}{lrccccc} 
& Español & Mulato & Mestizo & Indio & Esclavo & Otros \\
\hline Hombre & 9 & 110 & 11 & 102 & 9 & 76 \\
Mujer & 10 & 109 & 18 & 120 & 3 & 65
\end{tabular}

La población era mayoritariamente india, un 34' $58 \%$, con escasa diferencia respecto a los mulatos, un $34^{\prime} 11 \% \%^{41}$ pero si se tiene en cuenta que los esclavos que había en este latifundio eran mulatos, este porcentaje se eleva hasta el $35^{\prime} 98 \%$. Al ser una hacienda grande contaba con una casa principal donde estaban igualmente censados algunos de estos esclavos

39 Serrera Contreras, R.: Guadalajara ganadera... págs. 309-311.

40 Lafora, N.: Relación..., pág. 259.

41 Sin embargo, la cifra de población mulata no sería exacta si tenemos en cuenta la clasificación que se refleja en el documento original. Hemos comprobado que en las familias donde el marido es mulato y la esposa mestiza, los descendientes aparecen como mulatos en unas ocasiones y como coyotes en otras. Según Isidoro Moreno Navarro, el coyote es el resultado de la unión de mestizos e indios, mientras que el mulato es la conocida mezcla de españoles y negros; la denominación étnica correcta para los descendientes de mulatos y mestizos es calpamulato, pero para evitar errores constan en nuestros cuadros en la categoría de "otros". Moreno Navarro, Isidoro: Los cuadros del mestizaje americano. Estudio antropológico del mestizaje. Madrid, 1973, págs. 97, 101 y 131. 
como sirvientes, mientras otros aparecen registrados en viviendas independientes. Algo más elevada que en la hacienda anterior, aunque todavía escasa, es la presencia española, siempre registrada en cargos como administrador, llavero o ayudante.

Pozo Blanco, Sierra Hermosa y el rancho Aguanueva pertenecían al municipio de Pozos y por este motivo el censo de 1774 está firmado por el alcalde mayor de esta localidad; ${ }^{42}$ figura en el documento la cifra total de población de las dos haciendas del conde de San Mateo de Valparaíso, por lo que es posible realizar una comparación temporal:

\begin{tabular}{lcc} 
& Censo 1774 & Censo 1779 \\
\hline Pozo Blanco & 482 & 389 \\
Sierra Hermosa & 604 & 642 \\
TotAL & 1.086 & 1.031
\end{tabular}

Se produce en estos cinco años un decremento de algo más del 5\%, lo que tampoco es demasiado significativo. No obstante, en el año 1768 Lafora indicaba una población de 900 personas entre las dos haciendas y, pese a que esta cifra carece de la exactitud de las anteriores, reflejaría una tendencia al alza.

\section{Gruñidora}

Veinticuatro leguas en dirección norte, por una serranía de lomas suaves y de paisaje árido casi deshabitado, se encontraba la hacienda de Gruñidora. Alonso de la Mota explicaba el origen de tan curioso nombre:

"[...] Porque en todo este distrito no hay más que una fuente de agua que llaman la Gruñidora, y tan mala que ni aún los animales la beben, y si alguna gente la bebe es grandísimo el ruido que dentro del vientre hace, y así por esta razón le pusieron el nombre de la Gruñidora. El mismo efecto lo hace en las mulas y caballos, y si la echan en algún vaso de plata lo mancha y pone pardo". ${ }^{43}$

42 Los padrones de 1774 están firmados por el alcalde del distrito, el sacerdote o el administrador de la hacienda correspondiente, pero sin embargo los de 1779 están sin rubricar.

43 Mota y Escobar, A.: Descripción..., pág. 73. La pésima calidad del agua de este manantial es confirmada por Lafora (Relación..., pág. 257): “[...] En Gruñidora hay un ojo de agua muy mala para las personas, y particularmente para las bestias". 
Aunque ya en la segunda mitad del siglo XVIII un cronista describía Gruñidora como un conjunto de casuchillas con poca población, ${ }^{44}$ en el censo de 1774 esta hacienda consta con un total de 484 trabajadores, que se convertirán en 815 en el padrón de 1779. En ese breve espacio de tiempo se produjo un aumento significativo de la población, casi duplicando su tamaño, hasta superar a las haciendas que tradicionalmente han sido las más importantes como Cedros o Bonanza. En 1779 era la hacienda más poblada de toda esta jurisdicción, con 146 familias, y contaba con una capilla propia que prestaba ayuda en las labores religiosas a la parroquia del Real de Mazapil, celebrándose en ella misa todos los domingos y días feriados, además de oficiarse matrimonios y bautismos. ${ }^{45}$

Según consta en el encabezamiento del padrón, en 1779 era propiedad de don Juan Antonio Yermo, vecino de México, aunque con anterioridad había pertenecido al alférez Pedro de Arteaga, de San Luis Potosí. Los hermanos Yermo, Juan Antonio y Joaquín Gabriel, procedían de la aldea de Sodupe, en el Valle de la Gordejuela (Vizcaya), en la segunda mitad del siglo XVIII emigraron a México ${ }^{46}$ y ya en 1778 son grandes comerciantes miembros del Consulado de la capital mexicana. Parte de su fortuna la destinaron a inversiones, concediendo prioridad a las haciendas azucareras ${ }^{47}$ $\mathrm{y}$ a las zonas mineras.

En las relaciones mercantiles el nepotismo era más que frecuente, llegando incluso a aparecer un estereotipo, el del inmigrante que se gana la confianza del pariente rico y se casa con su hija, despojando al hijo de su legítimo patrimonio. Precisamente uno de los sobrinos de los Yermo - Gabriel Patricio Yermo- también marchó a México y consiguió unirse en matrimonio a su prima, ${ }^{48}$ heredando así todas las propiedades del acaudalado tío. A pesar de no poseer ningún título de nobleza, los Yermo vivían como tales; su condición de peninsulares y ricos atrajo a toda una corte de parientes y criados, que ellos mantenían. Así, por ejemplo, Gabriel Yermo llegó a tener a su cargo 42 personas: su mujer, cinco hijas, un hijo, veintisiete sirvientes y un capellán criollo. ${ }^{49}$

44 Ibídem.

45 AGI, Guadalajara, 543, cuaderno 1, fol. 124v. Expediente sobre el seminario conciliar de Guadalajara.

46 Brading, D. A.: Mineros y ..., pág. 158.

47 Langue, F.: Los señores..., pág. 305.

48 Hija ésta de Joaquín Gabriel Yermo. Ladd, D. M.: La nobleza..., pág. 43.

49 Ibídem. 
La hacienda propiedad de esta familia, como la mayoría en este distrito, estaba dedicada a la cría de ganado menor y a la minería, y por ello aparecen en el padrón algunas ocupaciones como carbonero o pastor. En esta hacienda la población es sobre todo india (43'31\%), porque los guachichiles originarios de esa zona eran nómadas pero, después de la pacificación, se asentaron en aquellos territorios que más tarde quedarían incluidos en los grandes latifundios de esta jurisdicción. En concreto el número de individuos que habitaban esta hacienda, clasificados según su raza, era el siguiente:

\begin{tabular}{lccccc} 
& Español & Indio & Mulato & Mestizo & Otros \\
\hline Hombre & 22 & 184 & 97 & 29 & 82 \\
Mujer & 20 & 169 & 98 & 31 & 83
\end{tabular}

Como particularidad de esta finca cabe señalar que el número de hombres era ligeramente superior, en porcentajes le corresponde un 50'79\%. Los matrimonios se produjeron a edad temprana y mientras en las primeras viviendas las familias constituyen una unidad étnica homogénea, en las que se sitúan en la periferia los cabezas de familia tienen una raza distinta a la de la cónyuge.

\section{Sabana Grande}

Había que recorrer diez leguas en dirección noroeste para llegar a este rancho desde la hacienda anterior. Parte del trayecto transcurría por el Camino Real de Guadalajara, ${ }^{50}$ que pasaba por esa ciudad.

Sabana Grande era un ranchito que pertenecía a Gruñidora, contaba con 28 trabajadores de los que sólo uno era español y el resto indios en su mayoría y algunos mestizos. ${ }^{51}$ Los que se casaron lo hicieron con alguno de su mismo grupo racial, demostrando que la endogamia en este lugar fue una práctica común y por tanto no se produjeron cambios étnicos dignos de registrarse. El número de hijos por familia oscilaba entre uno y cinco y casi todas las personas del rancho eran parientes entre sí.

50 Véase mapa: AGI, Mapas y Planos, México, 354. Mapa del Real y minas de San Gregorio del Mazapil.

51 De los 28 individuos, 24 son indios, 3 mestizos y tan sólo uno español. 
A medida que se iba avanzando camino al Real del Mazapil la serranía se elevaba, resultando el paisaje más agreste; hacia el norte se encuentra el pico Teria o Etéreo que es el más alto de toda la altiplanicie zacatecana ${ }^{52} \mathrm{La}$ cabecera de esta jurisdicción se encontraba situada en una llanura bordeada por cerros de menor altura, de ella partían caminos hacia el norte, noreste y sur y tomando el primero de ellos se llegaba a la villa de Saltillo.

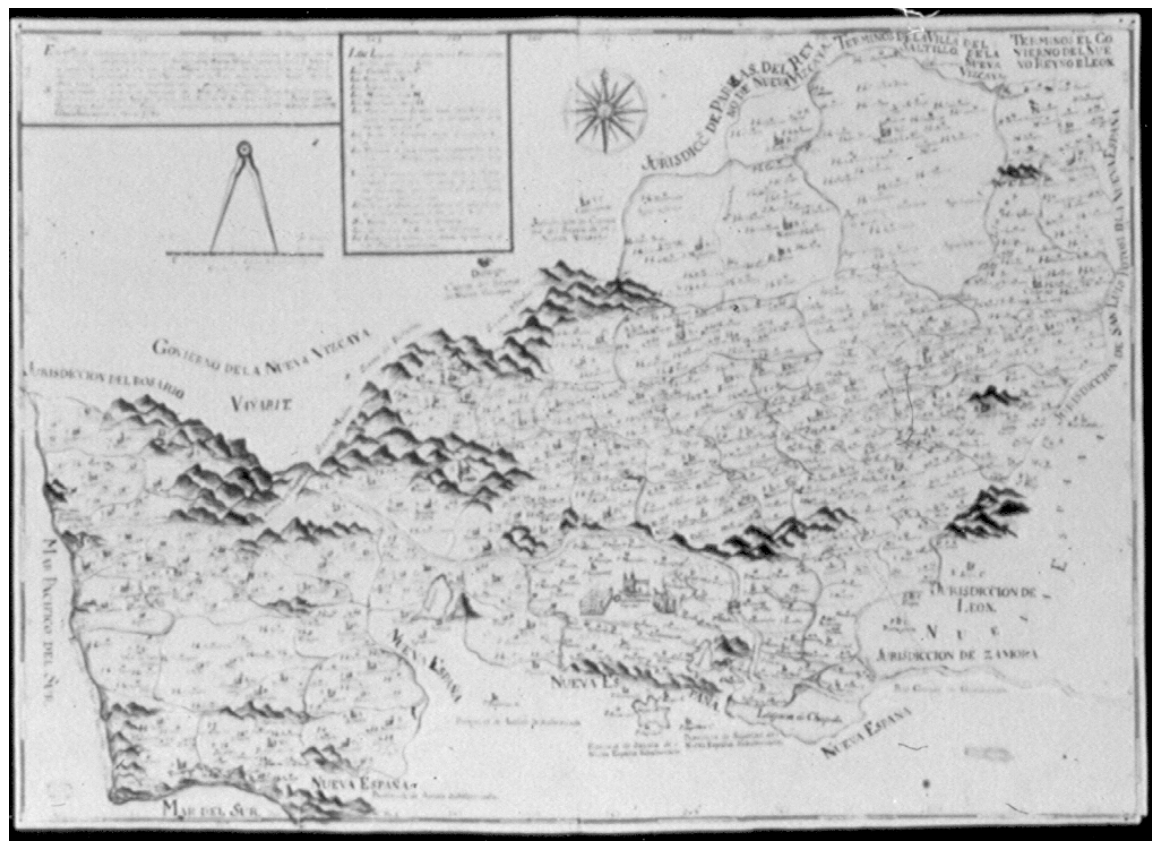

AGI, Mapas y Planos, México, 354. Mapa del Real y minas de San Gregorio del Mazapil

\section{Bonanza}

Tras la pacificación de los indios chichimecas y por los servicios prestados durante esa campaña bélica, Francisco de Urdiñola fue nombrado gobernador y capitán general de la Nueva Vizcaya, recibiendo además en forma de merced de tierra esta hacienda de Bonanza, entre otras propiedades. ${ }^{53}$ El licenciado Gaspar de la Fuente escribía lo siguiente:

52 Lafora, N.: Relación..., pág. 255.

53 Morfi, Fray Agustín de: Viaje de indios y diario del Nuevo México. Edición de Vito Alessio Robles. México, 1935, págs. 267-270. 


\begin{abstract}
"En el Mazapil hay dos haciendas, una del gobernador Francisco de Urdiñola, cuyos metales se muelen y labran en las dichas minas y se traen a beneficiar a dos haciendas de agua, una que tiene en la Vizcaya, 22 leguas de las dichas minas, y otra en la jurisdicción de Sombrerete, que está a 34 leguas del Mazapil y otra de un ingenio de mulas que está en un paraje que llaman Bonanza, cuatro leguas de las dichas do están rancheados algunos indios guachichiles que sirven en la dicha hacienda. Saca en cada un año en todas tres, según dicen, más de 100.000 pesos". ${ }^{54}$
\end{abstract}

Una de las herederas de Urdiñola - Francisca Valdés Alcega y Urdiñola- se casó con Agustín Echeverz y Zubira, quien en 1682 obtendría el título del marquesado de San Miguel de Aguayo. El primer marqués era caballero de la Orden de Santiago, gobernador y capitán general del Nuevo Reino de León y alguacil perpetuo y hereditario del Reino de Navarra. ${ }^{55}$ En la línea sucesoria de estos nobles se encuentra otro prototipo de la América colonial, el del inmigrante que consigue toda su fortuna mediante provechosos enlaces matrimoniales; tal es el caso de Francisco Valdivieso, primer conde de San Pedro del Álamo. En primeras nupcias se había desposado con Luisa Sánchez de Tagle, hija del segundo marqués de Altamira, que aportó al matrimonio, junto con una generosa dote, un banco de plata destinado a la concesión de créditos a los empresarios mineros. $\mathrm{Al}$ no poseer descendencia concertó don Francisco un segundo matrimonio con la tercera marquesa de San Miguel de Aguayo - María Josefa Echevers- y fruto de este matrimonio fueron sus dos únicos descendientes José Francisco y Pedro Ignacio Valdivieso Echevers. ${ }^{56}$

Con el matrimonio Valdivieso-Echevers la fortuna de los Aguayo alcanzó su máximo nivel, pero a la muerte de los progenitores y debido a la minoría de edad de sus descendientes, la herencia quedó en manos del sobrino del conde, —el general Francisco Manuel Sánchez de Tagle. ${ }^{57} \mathrm{La}$ mala administración del albacea, junto con los excesivos gastos de la familia, motivó que en 1779, cuando el cuarto marqués de Aguayo heredó su fortuna, a duras penas pudo cubrir todas las deudas heredadas, de casi medio millón de pesos ${ }^{58}$ suponiendo una cantidad cercana al doble de sus

54 Berthe, J.P.: "El licenciado...”, págs. 106-108.

55 Atienza, J.: Títulos nobiliarios..., págs. 263-267.

56 Brading, D. A.: Mineros y..., págs. 237-238.

57 Vargas-Lobsinger, María: Formación y decadencia de una fortuna. Los mayorazgos de San Miguel de Aguayo y de San Pedro del Álamo, 1583-1823. México, 1992, págs. 83 y siguientes.

58 Brading, D. A.: "Gobierno y élite en el México colonial durante el siglo XVIII". En Historia Mexicana, volumen 23, n. ${ }^{\circ}$ 4, México, abril-junio 1974, págs. 611-645. 
ingresos anuales en la ciudad de México. ${ }^{59}$ Sin embargo, era poseedor de uno de los mayores latifundios de la Nueva Galicia que, con centro en el municipio de Patos, se extendía desde las localidades de Saltillo y Castaño hasta Mapimí, Parras y Mazapil. En este último distrito, además de la hacienda de Bonanza, poseía la estancia de ganado denominada Santiago y los ranchos de Santa Elena, Aguadulce y Buenaventura ${ }^{60}$ Entre todas estas propiedades, incluyendo trabajadores fijos y aquellos jornaleros eventuales, en el año 1768 Lafora estima una población aproximada de 2.000 personas:

"En lo alto del puerto de Canutillo se aparta otro camino, para la hacienda de Bonanza, que sólo dista $1 / 2$ legua al sur, donde se trabaja unas razonables minas de plata de beneficio al fuego, lo que junto con las labores y otras ocupaciones, hace ascender su población a 2.000 almas". ${ }^{61}$

Si se tiene en cuenta tan sólo la hacienda de Bonanza,${ }^{62}$ el padrón de 1779 arroja cifras más exactas, con un total de 584 trabajadores, de los que un $48^{\prime} 45 \%$ son indios y constituyen el grupo mayoritario. Analizando con mayor detalle las cifras que se encuentran en el expediente se obtiene que:

\begin{tabular}{lcccccc} 
& Español & Mulato & Indio & Mestizo & Esclavo & Otros \\
\hline Hombre & 27 & 74 & 141 & 8 & 2 & 56 \\
Mujer & 12 & 70 & 142 & 4 & 2 & 46
\end{tabular}

Comparando ésta con otras haciendas, el número de españoles era superior; éstos vivían en casa aparte, poseyendo esclavos en calidad de sirvientes. El latifundio contaba con capellán propio (don José del Castillo y Barrera en esas fechas), pero también disponía de barbero, mayordomo, velador, administrador y tres caseros, todos ellos españoles. Los ocupantes de estos cargos descritos anteriormente, permanecieron solteros o se casaron con españolas y aunque en este mismo padrón también aparecen matripág. 37.

59 Anna, Timothy E.: La caída del gobierno español en la ciudad de México. México, 1978,

60 AGI, Guadalajara, 348. Plan general de curatos en la Nueva Galicia, expediente del real de minas de San Gregorio de Mazapil.

61 Lafora, N.: Relación..., pág. 254.

62 En el inventario de propiedades de los marqueses en el año 1751, figura la hacienda de Bonanza junto con sus minas, que suponen un 51 ' $11 \%$ de todas sus riquezas. Vargas-Lobsinger, M.: Formación y..., pág. 93. 
monios mixtos entre indias y españoles, éstos últimos no habitaban en las casas principales.

Como la actividad de la hacienda era el beneficio de metales por fundición, entre los indios había algunos obreros especializados, que en el documento original constan como "afinadores".

\section{Punta Santa Elena}

Todavía dentro de los límites del marquesado de Aguayo, y a 16 leguas al norte de la hacienda principal, se situaba esta ranchería. En Punta de Santa Elena tan sólo había seis casitas con 29 personas, de las que 22 eran mulatos y el resto mestizos, existiendo entre la mayoría de ellos algún tipo de parentesco; tal fue el caso de la familia León, que ocupaba la mitad de las viviendas del rancho. Los hermanos menores — José y Marcelo- se casaron jóvenes y con mujeres de su misma raza, mientras que Ana - la hermana mayor - contrajo nupcias con un mestizo, siendo éste el único caso de matrimonio mixto.

Casi todas estas estructuras familiares pueden encuadrarse en la categoría de "familia simple", ${ }^{63}$ donde el número de hijos se encuentra comprendido entre 1 y 4.

\section{San Buenaventura}

Siete leguas algo más al norte, casi en los límites de la localidad de Saltillo, se encontraba el rancho de San Buenaventura, del mismo propietario que los anteriores. En el censo de 1779 figuraba con la siguiente inscripción:

"Padrón del rancho de San Buenaventura, perteneciente a la hacienda de Bonanza, del marqués de San Miguel de Aguayo". ${ }^{64}$

Era un rancho mediano pues tan sólo contaba con un total de 96 trabajadores. Por primera vez en lo que vamos recorriendo los españoles constituían un grupo poblacional importante, en concreto el 37'5\%, mientras

63 Román Gutiérrez, J. F.: “Mazapil...”, pág. 230.

64 AGI, Guadalajara, 348. Expediente formado... 
que mestizos y mulatos eran los grupos minoritarios. Analizando con más detalle las cifras del documento estudiado se obtiene que:

\begin{tabular}{lccccr} 
& Español & Mulato & Indio & Mestizo & Otros \\
\hline Hombre & 19 & 4 & 20 & 3 & 9 \\
Mujer & 17 & 4 & 12 & 3 & 12
\end{tabular}

$\mathrm{Al}$ ser este censo mucho más completo, permite llevar a cabo un estudio teniendo en cuenta la ocupación que desarrolla cada uno de estos individuos.

\begin{tabular}{lc} 
Ocupación & Número de individuos \\
\hline Maestro & 1 \\
Arriero & 8 \\
Operario de mina & 1 \\
Vaquero & 6 \\
Pastor & 1
\end{tabular}

A lo largo del siglo XVIII la arriería se convirtió en una actividad alternativa para muchos de los miembros de los estratos inferiores de la población ${ }^{65}$ y en este rancho eran sobre todo españoles los que ejercían esa profesión. El ganado era custodiado generalmente por indios, mientras que los mulatos se ocupaban en labores mineras prestando sus servicios en la hacienda principal (Bonanza), puesto que era la ganadería la actividad básica también en este rancho.

\section{San Isidro}

Junto con Cedros, pertenece al conjunto de haciendas propiedad de Juan Lucas Lazaga, otro de los grandes mineros de Nueva Galicia. Vecino de la ciudad de México, constituye otro prototipo de acceso a la élite mediante ascensos en la jerarquía burocrática, ostentando los cargos de regente y contador de menores. En 1777, con Joaquín Velázquez de León,

65 Serrera Contreras, R. M.': Tráfico terrestre..., pág. 224. 
Lazaga fundaría el Tribunal de Minería, institución representativa de todos los mineros novohispanos, que también ambos llegarán a dirigir. ${ }^{66}$

Situada 22 leguas al suroeste de la cabecera del distrito, esta fue la hacienda que tuvo el mayor incremento de población. En el censo de 1774 aparece con 281 habitantes, para pasar a 642 cinco años más tarde, es decir, un aumento del $128{ }^{\prime} 46 \%$, lo que supone más del doble de la plantilla inicial. En concreto en 1779 la población aparecía distribuida de la siguiente forma:

\begin{tabular}{lccccc} 
& Español & Mulato & Mestizo & Indio & Otros \\
\hline Hombre & 6 & 178 & 11 & 25 & 80 \\
Mujer & 9 & 199 & 3 & 33 & 98
\end{tabular}

Ya hemos indicado que en otras haciendas eran los mulatos el grupo mayoritario, pero es en San Isidro donde constituyen el porcentaje más elevado de todo el distrito (suman un 58'72\%); y como viene siendo la tónica general, los españoles se encuentran entre los grupos menos numerosos.

\section{Cedros}

Fue la más antigua y conocida de todas las haciendas y de ella dependían las estancias de Carbonera del Pico, Salvador, Guatepamil, Caopan y los ranchos de Caocha, Carrizal y Ovejas. Su dueño en 1774 era Juan Lucas Lazaga, pero con anterioridad perteneció a Juan Guerra de Resado ${ }^{67}$ y a la familia Martínez Martaraña ${ }^{68}$ En 1606, Alonso de la Mota escribía sobre la denominación de esta hacienda:

"Saliendo de aquí cinco leguas hacia el sur se va a otro Real de minas que llaman de los Cedros donde ay dos ingenios de agua que benefician metales por fundición, son algunos de buena ley y así se saca mucha plata, es esto en la doctrina y justicia sujeto al Mazapil de temple frío, y sano, y de buenas aguas. Tiene en sus alrededores fra-

66 Para ampliar información sobre esta institución véase Moreno de los Arcos, Roberto: "Minería" en Los tribunales de la Nueva España. Antología, introducción y edición de José Luis Soberanes Fernández. México, 1980, págs. 267-281.

67 Berthe, J.P.: "El licenciado...”, pág. 120. págs. 33-177.

68 González Navarro, M.: Repartimiento de indios en la Nueva Galicia. México, 1953, 
gosas montañas de arboleda silvestres y desta lo que más abunda son Cedros que los ay hermosísimos y por esta causa tomó este Real nombre de los Cedros". ${ }^{69}$

También Gaspar de la Fuente, en el año 1608, describió Cedros como sigue:

"Cuatro leguas antes de llegar al Mazapil hay un paraje que llaman San Juan de los Cedros do están rancheados hasta 30 indios guachichiles y allí tienen poblada una hacienda de agua, Juan Guerra de Resado tiene tres ingenios con 8 hornos de fundición y un ingenio de afinación; e los metales que se benefician se traen del Mazapil do tiene para molerlos un ingenio y un lavadero. Los dichos indios guachichiles le están encomendados y se aplican a servirles por su salario, y así no gasta Su Majestad con ellos ninguna cosa. Tiene para el servicio de esta hacienda dos españoles, tres mestizos y 10 esclavos; está arrendada esta hacienda en 64.000 pesos, de que se dieron por pagados sus acreedores por tiempo de 4 años. Sácanse en cada un año de esta hacienda 50.000 pesos". $^{70}$

Pero a partir de la segunda mitad del siglo XVIII es cuando Cedros aparece como una unidad económica y social, "hacienda de campo y de beneficio, y formaba un verdadero villorrio, con su iglesia, su cárcel, sus diferentes talleres y oficinas: en 1774, había allí fundidores, refinadores y obreros de las haciendas de beneficio, carpinteros, herreros, albañiles y artesanos de todas clases". ${ }^{71}$ Era tal la importancia de esta hacienda que en 1805 el obispo de Guadalajara sugirió que se mantuviera un sacerdote fijo en Cedros para atender las necesidades eclesiásticas de la numerosa población de la finca:

"El día cuatro de Septiembre hizo su Señoría Ilustrísima la visita local de la capilla de la hacienda de Cedros ayuda de parroquia del curato de Mazapil y por hallarse dotada de Vasos Sagrados, Pila Bautismal, y demás necesario para su decencia y ornato, dio por visitada y pasada en cita general su licencia. Y en atención a la basta feligresía de su comprehención, mandó que del cura del Mazapil mantenga siempre en dicha hacienda un ministro de pie fijo, que cumpla con las obligaciones correspondientes a quien hace veces segura". ${ }^{72}$

En el padrón de 1779 figuraba como una hacienda minera, mencionando oficios como fundidores, afinadores y operarios de mina. Pero existe constancia de que también en este latifundio se trabajaba la tierra de cultivo

69 Mota y Escobar, A.: Descripción..., pág. 72.

70 Berthe, J. P.: "El licenciado...", págs. 106-107.

71 Langue, F.: Los señores..., pág. 304.

72 AGI, Guadalajara 543, cuaderno 1, folio 125. Expediente sobre el seminario conciliar de Guadalajara. 
y sobre esta actividad Lafora escribió, quizás exageradamente, que "se recogen en ella además de diferentes semillas, muy buenas uvas, de que hacen un vino tinto, el mejor de América". ${ }^{73}$ Además, durante los siglos XVII y XVIII se emitieron peticiones de concesión en encomienda, con carácter temporal, de indios segadores y pajareros para la recolección de la cosecha en Cedros.

En 1779 la población aparecía distribuida allí de la siguiente forma:

\begin{tabular}{lcccccc} 
& Español & Mulato & Mestizo & Indio & Esclavo & Otros \\
\hline Hombre & 36 & 87 & 29 & 65 & 21 & 139 \\
Mujer & 35 & 99 & 37 & 97 & 10 & 139
\end{tabular}

De todas las haciendas del distrito, Cedros era la que poseía mayor número de esclavos y esto, en parte, evidencia que la minería fue su principal actividad. Es original el hecho de que la mayoría de los trabajadores pertenecieran al último de los grupos, es decir, aquel que reúne toda una serie de denominaciones étnicas como lobo, coyote, calpamulato; la conclusión que se desprende de este hecho es que el mestizaje era un fenómeno muy arraigado entre la población de este latifundio.

\section{San Tiburcio}

Veinte leguas era la distancia que separaba a esta hacienda de la de Cedros, aunque siguiendo este camino era necesario pasar antes por la cabecera del distrito minero situada a catorce leguas de San Tiburcio. Perteneciente a Juan Miro, vecino de México, era una propiedad poco relevante que, sin embargo, aparece en el expediente con la denominación de hacienda, lo cual es bastante contradictorio pues otras fincas con más población y mayor número de viviendas reciben el nombre de ranchos. ${ }^{74}$ No

73 Lafora, N.: Relación..., pág. 236.

74 La diferencia entre rancho, hacienda y estancia es analizada por Ramón Serrera basándose en: "La Descripción de la diócesis de Guadalajara de Indias" (1770) de Mateo José de Arteaga. Ranchos son aquellas propiedades donde "viven pocas gentes con pocos bienes y albergados en chozas", mientras que haciendas son "las que tienen casas grandes y bastantes familias"; por último, la estancia es aquella propiedad que mantiene una única actividad económica, cuenta con una gran extensión territorial pero escasamente poblada. Serrera, R. M. a: Guadalajara ganadera..., págs. 35-36. También Taylor analiza detenidamente el concepto de hacienda y en su estudio situado en la zona de Oaxaca, la define como "una extensión de tierra rural con una economía mixta de ganadería y agricultura, construcciones permanentes y con trabajadores residentes". Taylor, William B.: "Landed society in New Spain: A view from the South". The Hispanic American Historical Review, vol. 54, n. 3, agosto 1974, págs. 387-413. 
obstante, esta propiedad, al igual que las haciendas más importantes, contaba con capilla propia. ${ }^{75}$

Habitada por un total de 37 personas, éstas se distribuían en siete viviendas; la mayoría eran indios (18) aunque también había mestizos (14) y mulatos (2), resultando que tan sólo se registraron tres individuos de otras etnias. Destacaba la total ausencia de peninsulares y criollos, pues en esta propiedad no habitaba ni un español, lo cual viene a fortalecer la idea que indicamos al principio de la escasa importancia de esa presencia. Los matrimonios se celebraban generalmente entre individuos de una misma etnia y el número de descendientes solía oscilar entre 1 y 9 , con una media de 3'14 hijos.

\section{Tráfico comercial}

Era precisamente el intercambio la razón principal para que la Corona decidiera articular toda la red de caminos que surcaban la Nueva España, aunque este tráfico mercantil interno no era desconocido en el México prehispánico. Entre los objetos que se usaban en el intercambio, Román cita piedras preciosas, sal, conchas, plumas, pieles, obsidiana tallada y hasta imágenes de dioses. ${ }^{76}$ Para estudiar el uso que se le daba a estas rutas ya en la época colonial lo más lógico sería cuestionarse ¿qué tipo de mercancías circulaban?, ¿cómo eran transportadas? y ¿por quién?.

A finales del siglo XVIII había en Mazapil ocho minas de cobre, seis de plata y dos de oro y un total de siete haciendas de beneficio ${ }^{77}$ y el mineral extraído de ellas era transportado hasta Zacatecas en carretas. En la mayoría de los casos el acarreo de los metales estaba en manos de unos cuantos grandes empresarios del transporte, sin embargo en ocasiones eran los propios mineros los que trasladaban sus mercancías. En un asiento de arrieros de 1800 se mencionan dos transportes con destino a Mazapil: el primero realizado por Pedro Agustín de Anaya, dedicado profesionalmente a la arriería, y el segundo por la marquesa de Jaral del Berrio. ${ }^{78}$

75 AGI, Guadalajara, 543. cuaderno 1, folio 124v. Expediente sobre el seminario conciliar de Guadalajara.

76 Román Gutiérrez, J. F.: “El Camino...”, pág. 11.

77 Florescano, E. y Gil, I.: Descripciones económicas regionales de Nueva España. Provincias del Norte. México, 1976, pág. 98.

78 Suárez Argüello, C. E.: Camino real y carrera larga. La arriería en la Nueva España durante el siglo XVIII. México, 1997, apéndice II. 
Paralelamente a la producción minera se desarrolló la ganadería, convirtiéndose ésta última en la principal actividad económica de la zona. Ya desde principios del siglo XVII los cronistas mencionaban la increíble proliferación del ganado en estos lugares:

"[...] De tierra despoblada muy llana, y falta de agua porque ay un ganado mayor alzado y muchas liebres, y gran suma de benados que aca llaman berrendos son todos manchados de un color vayo y blanco y andan en manadas a la contina y son sumamente ligeros y anssi nunca desamparan los llanos que son sus guaridas". ${ }^{79}$

Pero fue a lo largo del siglo siguiente - con las confirmaciones de títulos de propiedad de las tierras - cuando se establecieron las grandes haciendas y la cría de ganado en muchas de estas propiedades pasó de ser una ocupación complementaria a convertirse en la actividad principal. En el ocaso del XVIII, la producción ganadera anual era de 7.520 cabezas de vacuno, 470.000 cabezas de lanar macho y hembra, 42.000 de cabrío, 300 de porcino, 4.231 cabezas de ganado caballar hembra y 1.198 macho, 3.562 mulas y 535 asnos. $^{80}$

Las principales ferias ganaderas del virreinato se celebraban entre los meses de septiembre y octubre, y teniendo en cuenta que el acarreo del ganado duraba aproximadamente un mes, era necesario comenzar el transporte de las reses en agosto. ${ }^{81}$ Hasta lugares como Toluca, Puebla o ciudad de México llegaba el ganado que provenía del norte de Nueva Galicia y en estos mercados provinciales eran los nobles los que monopolizaban el comercio de carne. Como ejemplos representativos de este hecho, Ladd cita el caso del conde de Medina, que proveía de reses a Puebla, Orizaba, Córdoba y Veracruz; o el repetidamente citado marqués del Jaral de Berrio, que se encargó de los mercados de San Luis Potosí y Guanajuato. ${ }^{82}$ Sin embargo, en el transporte del ganado estos nobles asumían una serie de riesgos, derivados de las distancias y las sequías prolongadas. Muchas reses morían por deshidratación y las que sobrevivían quedaban tan flacas que el beneficio obtenido por su venta bajaba mucho. No fueron pocos los pleitos que surgieron cuando el ganado se escapaba en busca de agua, destruyendo cercas o dañando pastizales y, sobre todo, campos de cultivo. ${ }^{83}$

\footnotetext{
79 Mota y Escobar, A.: Descripción..., pág. 72.

80 Florescano, E. y Gil, I.: Descripciones económicas..., págs. 99-100.

81 Serrera R. M. a: Guadalajara ganadera..., págs. 97-98.

82 Ladd, D. M.: La nobleza..., págs. 68-71.

83 Ibídem.
} 
No obstante, el coste en mano de obra era mínimo, pues para la conducción de este ganado no se necesitaba demasiado personal. Thomas Calvo afirma que sólo eran empleadas tres o cuatro personas para encaminar más de 3.000 cabezas. ${ }^{84}$ Los grandes rebaños — de 2.000 a 3.000 reses - eran conducidos generalmente por el mayordomo de la hacienda, mientras que los criadores medianos se ponían de acuerdo para contratar a un acarreador profesional. ${ }^{85}$ Tal es el caso del capitán Pedro de Anda, que se dedicó al transporte masivo de ganado desde la Nueva Vizcaya hasta ciudad de México. ${ }^{86}$ También existían empresarios que se desplazaban hasta las zonas productoras ganaderas para adquirir rebaños, generalmente los de menor tamaño; solían llevar a sus propios trabajadores, que se encargaban de transportar y vender la mercancía en las diferentes ferias.

Aunque no eran tan importantes en volumen como las producciones anteriormente señaladas, también en Mazapil se elaboraban jabón, vino y aguardiente, que anualmente se enviaban a Zacatecas. ${ }^{87}$

Uno de los principales problemas que afectaron a esta región fue el abastecimiento de mercancías, sobre todo de alimentos, y ya desde los inicios de la colonización de estos lugares del distrito de Mazapil siempre fue evidente la dependencia respecto de Zacatecas en cuanto al suministro. En 1604, Alonso de la Mota afirmaba que "llévase todo lo necesario de Zacatecas, a estas minas en carretas anssi ropas como bastimentos". ${ }^{88}$

De hecho, tanto al norte como al sur de Mazapil había centros productores de granos, como Saltillo, Parras, Súchil o Poanas, pero su escasa producción era absorbida por los reales de minas cercanos, por lo que no existía margen alguno para la redistribución. Por ello Bakewell afirma que el volumen de grano que llegaba a Zacatecas era insuficiente ${ }^{89}$ y se impuso entonces la necesidad de acarrear los cereales necesarios para el abastecimiento de su población desde otras regiones situadas más al sur. Pero las distancias motivaban que el precio de los productos fuera mucho mayor. Por ejemplo, a finales del siglo XVIII en Tlaltenango el maíz se vendía a ocho reales la fanega, cuando llegaba a Zacatecas su precio había ascendido hasta diecisiete reales, para alcanzar los treinta y dos en Ma-

84 Calvo, T.: Por los caminos de Nueva Galicia: Transportes y transportistas en el siglo XVI. Guadalajara, 1997, pág. 56.

85 Serrera, R. M. ${ }^{\text {a: }}$ Guadalajara ganadera..., pág. 97.

86 Calvo, T.: Por los caminos..., págs. 40-44.

87 Florescano, E. y Gil, I.: Descripciones económicas..., pág. 94.

88 Mota y Escobar, A.: Descripción..., pág. 72.

89 Bakewell, P. J.: Minería y ..., pág. 92. 
zapil. ${ }^{90}$ Finalizando el siglo XVIII, para este real de minas era necesario importar anualmente 20.748 fanegas de maíz, 2.773 de frijol, 1.213 de chile, 1.200 cargas de harina, 20.000 pesos de efectos de Castilla, 2.000 pesos de efectos de China y 2.150 pesos de cacao y cera. ${ }^{91}$

\section{Seguridad en los caminos}

No obstante todo lo expuesto anteriormente, el tráfico era más bien escaso y es ello precisamente otro de los motivos de los espectaculares incrementos en el precio de las distintas mercancías. Gaspar de la Fuente afirmaba que: "El camino es muy poco cursado si no es de los interesados en aquellas minas". ${ }^{92}$ Como causas directas de esta ausencia de tránsito, el oidor cita el clima, la orografía de la región y la siempre presente escasez de agua; pero los ataques de indios chichimecas y el bandolerismo eran también factores a tener en consideración.

Aunque en 1590 finalizó la guerra del Mixtón, en los caminos, los asaltos de indígenas continuaban siendo frecuentes. Casi cien años después, en 1681, los oficiales reales de México informan que ningún arriero aceptaba transportar azogue a Parral debido al peligro que representaban los chichimecas. ${ }^{93}$ En pleno siglo XVII aún se considera este territorio "frontera de indios guachichiles que son bárbaros y de guerra", ${ }^{94}$ porque la belicosidad de esta tribu se vio incrementada por la crueldad de algunos encomenderos. De principios de esa misma centuria es el siguiente testimonio:

"[...] Y habiendo hallado que en estas minas tenían los mineros para los indios, calabozos y más ásperas prisiones que en otras ningunas partes, procedió contra ellos culpados en esta razón y en otros malos tratamientos y para la conservación de dichas minas en lo de adelante, y buen tratamiento de indios y mejor doctrina de ellos y de los negros y mulatos". ${ }^{95}$

90 Román, J. F.: “Mazapil ...”, págs. 13-14.

91 Florescano, E. y Gil, I.: Descripciones económicas..., pág. 93.

92 Berthe, J. P.: "El licenciado...", págs. 108-110.

93 Porras Muñoz, G.: La frontera con los indios de Nueva Vizcaya en el siglo XVII. México, 1980, pág. 375 .

94 Berthe, J. P.: "El licenciado...”, pág. 110.

95 Ibídem. 
Estas extremas condiciones de vida, junto con el consumo excesivo de alcohol, explican la frecuencia de los robos en los caminos, que en ocasiones terminaban en asesinatos. La mayoría de los asaltos - un 55\% tenía lugar de noche y generalmente en el período que media entre la siembra de Semana Santa y la recolección cerca de la Navidad. Como armas se usaban cuchillos y piedras, ya que los indios tenían prohibido por ley la posesión de armas de fuego y además éstas resultaban demasiado caras para ellos..$^{97}$

Aunque nos hemos referido anteriormente a los indígenas, también eran frecuentes los asaltos cometidos por españoles (peninsulares y criollos), aunque éstos últimos son los señalados por las autoridades cuando en los informes remitidos al rey tratan sobre el bandolerismo. Pero hay que destacar que no se trataba de auténticas bandas sino más bien de grupos formados por tres o cuatro miembros ligados por algún parentesco, aunque este fenómeno llegó a alcanzar tal importancia que fue necesario recurrir durante un tiempo a la Santa Hermandad de México y a su cuadrilla armada. En 1671, el fiscal de la Audiencia de la Nueva Galicia escribía al rey lo siguiente:

"Este reino es copioso e innumerable de bandoleros y gente perdida, los más españoles que habitan en los montes y estancias, comiendo maíz, vistiéndose sólo de lo que hurtan con que son muchas las muertes y los robos en los caminos". ${ }^{98}$

Sin embargo, a fines del siglo XVIII, estos peligros aún seguían existiendo. Por ello, los fundadores del Tribunal de Minería, ${ }^{99}$ con intereses en estas tierras de Mazapil — como ya se ha indicado—, se dirigían a Carlos III en 1774 exponiendo que:

"Todo se lleva a lomos de mulas a caminar centenares de leguas por caminos desiertos, difíciles y expuesto a los insultos de los indios enemigos o de bandoleros; de manera que llegan tarde y a precios tan altos que casi enteramente derogan la ventaja que se contaba sobre la riqueza del metal". ${ }^{100}$

96 Taylor, William B.: Drinking, homicide and rebellion in colonial mexican villages. Stanford, California, 1979, págs. 77-79.

97 Ibídem.

98 AGI, Guadalajara, 11, expediente 79, carta del 26 de marzo de 1671.

99 Véase el reciente libro de Eduardo Flores Clair, Minería, educación y sociedad. El Colegio de Minería, 1774-1821. México DF, 2000.

100 Chávez Orozco, L.: Minería en la Nueva España a postrimerías del siglo XVIII. Documentos para la Historia Económica de México, volumen XII. México, 1938, pág. 21. 


\section{Consideraciones finales}

Una de las características más destacadas de la sociedad americana es su riqueza étnica, derivada de la conjunción de tres razas originales: blanca, india y negra. ${ }^{101}$ En el siglo XVIII, que es el esencial marco temporal del presente trabajo, el mestizaje era ya un fenómeno plenamente desarrollado entre la población del norte de México. Uno de los aspectos más singulares de este proceso fue precisamente la rica terminología que generó, cargada de matizaciones, como torna atrás, morisco o castizo. Pero este mestizaje no sólo debe entenderse en un sentido biológico sino también cultural; ${ }^{102}$ en esa línea, fueron los trabajadores quienes más aportaron al desarrollo de este intercambio en las tierras norteñas ya que los descendientes de conquistadores y los funcionarios siempre se vieron a sí mismos como un grupo superior y entre ellos, la fidelidad al concepto de "pureza de raza" era la nota predominante.

La aristocracia novohispana, los grandes mineros, los ricos comerciantes y los más importantes hacendados eran peninsulares o criollos casi en su totalidad. Aunque la diferente procedencia los convertía en rivales para algunas cuestiones, solían aliarse al ver peligrar sus intereses económicos. Familias como los Yermo, los Fagoaga o los Aguayo, entre otras, ostentaban el poder económico y político, canalizándolo a través de instituciones como el Consulado de Comercio, el Tribunal de Minería o el Cabildo. Muchos de estos influyentes clanes, sobre todo aquellos con intereses en el comercio, apoyaron las ideas independentistas a pesar de ser peninsulares y de talante conservador. Timothy Anna resume esta idea afirmando que: "El mero lugar de nacimiento no podía anular el interés propio para determinar sus prioridades políticas". ${ }^{103}$ Este es el caso de Gabriel Yermo, que encabezaría el golpe de Estado de 1808 apoyado por el resto de comerciantes del Consulado de México. Otros miembros de la elite con intereses en Mazapil, como el marqués de Aguayo, adoptaron una postura más imparcial, prefiriendo esperar al desarrollo de los acontecimientos en España antes de pronunciarse a favor o en contra de la autonomía, paso previo a la independencia.

101 Sin embargo, estos tres grupos originales no eran homogéneos sino que presentaban una gama de matices raciales y culturales. Esteva Fabregat, Claudio: El mestizaje en Iberoamérica. Madrid, 1988, págs. 18-20.

102 Aunque mestizaje y aculturación son procesos diferentes, en la Nueva España a lo largo de todo el período colonial se produjeron ambos. Ibídem.

103 Anna, Timothy E.: La caída..., pág. 48. 
A finales de la época colonial, en Nueva España coexisten dos formas de vida diferentes: la urbana y la rural. En la primera interactuaban estas grandes y poderosas familias propietarias, mientras que la segunda permanecía totalmente ajena a las intrigas políticas o a los grandes avatares económicos virreinales. Para un trabajador de una de estas haciendas norteñas no había más ley que la administrada por el hacendado o el mayordomo en su lugar, no existía otra asistencia religiosa que la que recibía en la capilla del rancho y no conocía otra autoridad que la del capataz. En este sentido, estamos de acuerdo con William Taylor cuando afirma que, a lo largo de la época virreinal, la hacienda se va configurando como una unidad separada de la sociedad colonial. ${ }^{104}$

Todavía estaban vivos en la memoria los españoles que iniciaron el proceso de colonización, y las consiguientes imágenes del señor feudal, por consiguiente el prestigio social que otorgaba la posesión de tierras fue un elemento importante en el desarrollo de la propiedad rural en el norte de Nueva Galicia; sin embargo, la búsqueda del lucro económico supuso el factor de mayor peso en este proceso y la minería el eje principal de ese interés. A medida que estos centros mineros fueron adquiriendo mayores proporciones surgieron actividades como la ganadería, para solucionar el problema del abastecimiento de carne. Y aunque Mazapil continuó produciendo minerales, la extracción de metales preciosos fue efímera y la minería de la zona se vinculó más a otros materiales como el cobre o el plomo, que ocuparon un segundo lugar al configurarse la cría de ganado como actividad principal en estos lugares. También la arriería fue cobrando importancia relacionada sobre todo con el transporte de reses. Por su parte, la agricultura no tuvo gran desarrollo debido a las adversas condiciones climáticas, por lo que Mazapil siempre dependió de otros centros de producción agrícola. Ya en el siglo XVIII se pueden encontrar algunas industrias como las del jabón o el aguardiente, que eran de tipo artesanal y nunca supusieron una fuente importante de beneficio económico.

104 Taylor, William B.: Landlord..., págs. 7 y 123. 